\title{
Cool atoms make physics prize matter
}

Philip Ball

Wolfgang Ketterle of the Massachusetts Institute of Technology (MIT) and Carl Wieman and Eric Cornell of JILA, an interdisciplinary research centre in Boulder, Colorado, have won this year's Nobel Prize in Physics for their work in making and understanding Bose-Einstein condensates (BECs).

This new form of matter, a strange state in which a group of atoms behaves as a single particle, was first created in 1995 by Wieman and Cornell by cooling atoms of rubidium to within less than a millionth of a degree of absolute zero. Ketterle's group at MIT managed to make a condensate only months later.

The theoretical existence of BECs was first proposed by Albert Einstein in 1924, building on work by the Indian physicist Satyendra Nath Bose. All particles are either bosons or fermions. Quantum theory says that no two fermions can occupy the same quantum state, but that any number of bosons can, in principle, exist in the same state. Einstein predicted that, at very low
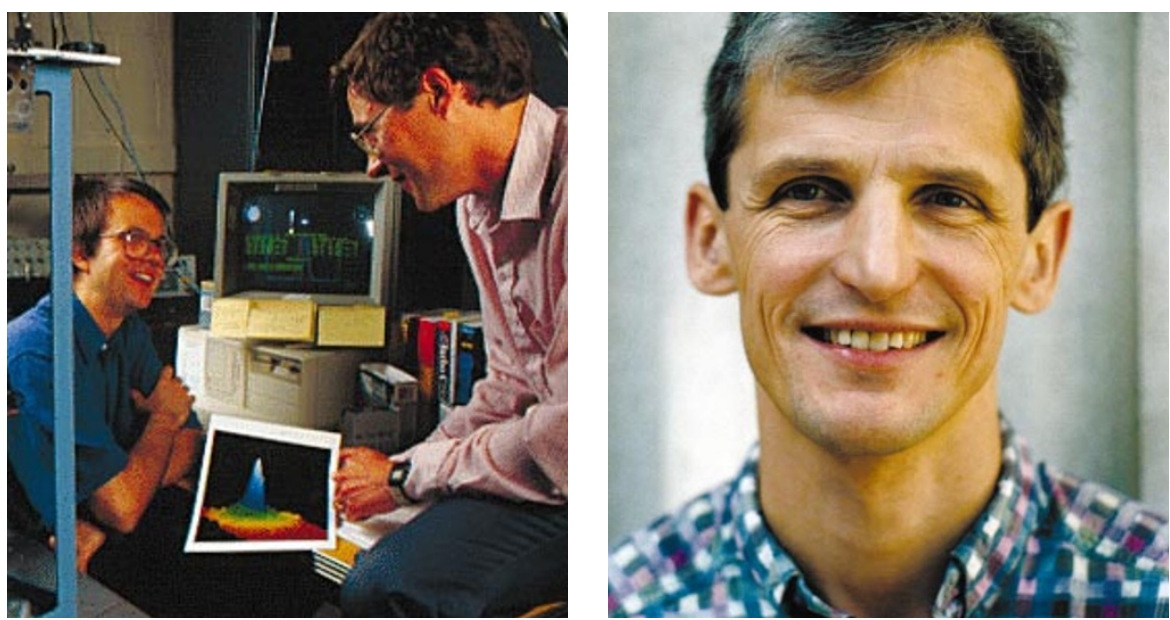

Winners: Eric Cornell and Carl Wieman, who made the first condensate, and Wolfgang Ketterle (right).

temperatures, all the particles in a sample of bosons - such as the rubidium atoms used by the JILA team — should fall into the same state and act as a single particle, later termed a BEC.

\section{Ig Nobels raise a welcome smile}

\section{Steve Nadis, Boston}

The organizers of the Ig Nobel prize ceremony, held to reward research "that cannot or should not be reproduced", faced a difficult decision this year. Should this lighthearted event be cancelled in view of the atrocities of 11 September? After some deliberation, the show went on - to the approval of a raucous crowd of 1,200 who gathered on 4 October in Harvard University's Sanders Theatre.

"There was a period of time shortly after the terrorist attack when it was difficult to think about things of consequence, let alone something like this," says Marc Abrahams, editor of the Annals of Improbable Research and the Ig Nobels' master of ceremonies.

"But I heard from a lot of people who wanted us to do it. I was both surprised and happy."

Nobel laureates who were asked to take part had mixed feelings. "I personally cannot muster any great enthusiasm for the Igs under the circumstances," Boston University physicist Sheldon Glashow told Nature. But other laureates, including Harvard chemist Dudley Herschbach, elected to participate. "I don't think it's disrespectful to move on and treat people to some fun," he says.

In the event, the tone was anything but sombre. The cast of Nobel laureates engaged in the usual shenanigans, singing in a première of an opera, The Wedding Complex, that culminated in the 60 -second wedding of two geologists, Lisa Danielson and Will Stefanov of Arizona State University.

As for the main act, Peter Barss of McGill University in Canada won the medicine prize for studying injuries caused by falling coconuts, while Chittaranjan Andrade and B. S. Srihari of the National Institute of Mental Health and Neuroscience in Bangalore snared the public-health prize for discovering that nose-picking is a common activity among adolescents. The psychology prize went to Lawrence Sherman of Miami University in Ohio for his ecological study of glee in preschool children, and Buck Weimer of Pueblo, Colorado, won the biology prize for inventing airtight underwear fitted with charcoal filters to remove foul-smelling gases.

John Keogh of Hawthorn in Victoria, Australia, was awarded the technology prize for patenting the wheel, sharing the honour with the Australian patent office. David Schmidt of the University of Massachusetts won the physics prize for considering why shower curtains billow inwards. And Michigan-based televangelists Jack and Rexella Van Impe earned the astrophysics prize for showing that black holes fulfil all the technical requirements of hell. The Van Impes did not attend the ceremony, but Massachusetts Institute of Technology astrophysicist Walter Lewin, accepting temporary custody of their award, said the finding "will force us to rethink all of our ideas about black holes".
The realization of BECs was longawaited, and Wieman and Cornell's 1995 paper (see Science 269, 198-201; 1995) caused a storm in the world of fundamental physics. Ketterle and his colleagues at MIT have subsequently clarified many of the properties of condensates. Together, the winners' work has made possible a host of other experiments that probe fundamental aspects of quantum theory.

Few prizes have been as widely predicted as this year's physics award. The original 1995 discovery was thought by many at the time to be worthy of a Nobel prize. Some physicists suspect that the physics prize in 1997, awarded to the pioneers of the atomtrapping technologies that Wieman, Cornell and Ketterle used to cool their atoms while undoubtedly deserved in its own right - was also given to prepare the path for honouring the breakthroughs at JILA and MIT.

Research into BECs is still highly active. Jakob Reichel and colleagues at the LudwigMaximilians University in Munich, for instance, have recently created an 'atom chip' in which electromagnetic fields control the movement of a condensate hovering above an electronic circuit (see Nature 413, 498-501; 2001). BECs are also allowing the investigations of imperfectly understood quantum phenomena such as entanglement (see Nature 413, 400-403; 2001). Entanglement will be one of the key features of future quantum computers.

Applications of the work are currently distant, although several possibilities exist. "I'm sure fascinating applications will happen," says Claude Cohen-Tannoudji of the École Normale Supérieure in Paris, one of the 1997 laureates. He cites the example of atom lasers, in which a beam of atoms from a condensate is used to build high-precision structures. The Nobel chemistry prize was announced after Nature went to press. For coverage, see isww.nature.com 